\title{
The importance of calf sensory and physical preferences for starter concentrates during pre- and postweaning periods
}

\author{
M. Terré, ${ }^{* 1}$ M. Devant, ${ }^{*}$ and A. Bach ${ }^{*} †$ \\ *Department of Ruminant Production, IRTA (Institut de Recerca i Tecnología Agroalimentàries), 08140 Caldes de Montbui, Spain \\ †ICREA (Institució Catalana de Recerca i Estudis Avançats), 08010 Barcelona, Spain
}

\begin{abstract}
We performed 3 studies to evaluate the effects of feed sensory and form preferences in young calves on performance and rumen fermentation dynamics. In experiment 1 , starter feeds containing wheat and soybean meal; wheat and canola meal; and oats and soybean meal were evaluated in 63 calves $(9 \pm 0.9 \mathrm{~d}$ old $)$. In experiment 2, 37 crossbreed female calves were used from 4 to $45 \mathrm{~d}$ of age (weaning) in a cafeteria study consisting of 4 different presentations of the same starter feed: meal, pellet, pellet mixed with whole-cereal grains (WHG), and pellet mixed with steamed-rolled cereal grains (SRG). In experiment 3, 63 Holstein male calves $(10 \pm 1.03 \mathrm{~d}$ old $)$ were randomly distributed to 2 treatments that consisted of feeding a pellet concentrate mixed with whole corn and barely grains (WHG) or the same pellet concentrate mixed with steamed-rolled corn and barley grains (SRG). In experiment 1, animals in all 3 treatments had similar intake and performance, and we found no differences in rumen fermentation parameters. In experiment 2, during the first week of study, calves had a greater preference for WHG; after the first week, calves had a greater preference for SRG. In experiment 3, starter concentrate intake was greater in WHG than in SRG concentrates between wk 5 and weaning. However, we observed no differences in growth or gain-to-feed ratio. Calves offered WHG concentrates had greater rumen $\mathrm{pH}$ and tended to have lower total rumen volatile fatty acid concentrations than those offered SRG concentrates. We concluded that preweaned calves preferred concentrates based on pellets mixed with steamed-rolled grains. When calves could not choose their starter feed, pellets mixed with steamed-rolled grains reduced concentrate intake and rumen $\mathrm{pH}$ compared to pellets mixed with whole grains, but performance was not impaired. Formulating starter concentrates according to calves' sensory and physical preferences had little effect on performance.
\end{abstract}

Received November 25, 2015.

Accepted May 8, 2016.

${ }^{1}$ Corresponding author: marta.terre@irta.cat
Key words: calves, choice, intake, performance

\section{INTRODUCTION}

The transition of dairy calves from a liquid to a solid diet is a crucial phase for ensuring sufficient concentrate and forage intake and avoiding a growth slump at weaning. Different feeding strategies have been studied at weaning to address this problem: (1) the use of feed additives to promote rumen development (Hill et al., 2009); (2) the use of ingredients with high sugar content to stimulate concentrate intake (Lesmeister and Heinrichs, 2005; Beiranvand et al., 2014); (3) changing the physical form of the feed (Bach et al., 2007; Terré et al., 2015); and (4) weaning groups of calves rather than individual hutches (Bach et al., 2010).

Miller-Cushon et al. (2014a) demonstrated that young calves have a marked preference for wheat, corn, and barley as energy ingredients, and for soybean as a protein ingredient. In contrast, young calves have a low preference for gluten feed, gluten meal, and canola meal. Montoro and Bach (2012) reported that calves given the opportunity to compose their own diet using 6 different ingredients in a cafeteria study were unable to balance their nutrient intake because they consumed excessive protein (without improving performance) compared with calves fed a starter feed balanced according to the NRC (2001) model. The findings of Miller-Cushon et al. (2014b) also demonstrated that calves had a high preference for soybean products. They found that calves had the capacity to sort in favor of soybean pellets in a starter concentrate composed of a mixture of 2 pellets, one containing soybean and the other containing the rest of the ingredients. It seems plausible to expect that formulating starter feeds for calves with highly preferred ingredients should enhance concentrate intake early in life.

Several studies have compared different feed presentations for dairy calves (Franklin et al., 2003; Bach et al., 2007; Terré et al., 2015), but studies evaluating calves' preferences for different feed form presentations are scarce. Bach et al. (2007) reported that solid feed consumption was greater in calves offered a multiparti- 
cle (or texturized) starter than in calves offered a meal starter feed, but interestingly, calves offered a meal feed were more efficient than those offered a multiparticle feed. Recent studies (Khan et al., 2011; Castells et al., 2012; Terré et al., 2015) have proposed feeding a concentrate pellet plus chopped hay or straw as an effective strategy for stimulating concentrate intake and increase rumen pH. However, Terré et al. (2015) compared a pelleted starter and chopped straw with the same starter offered either alone or as a mixture of pellet and whole corn and showed that calves eating the pelleted starter alone or with whole corn had similar rumen $\mathrm{pH}$ to calves eating the pelleted starter with straw. Several studies have shown that processing corn grain has little effect on calf performance (Bateman et al., 2009); whole corn and dry-rolled corn have been reported to improve concentrate intake most effectively (Lesmeister and Heinrichs, 2004).

The hypothesis of the present study was that offering preferred ingredients in a starter concentrate to young calves would be an effective practice for stimulating concentrate intake. We also hypothesized that if calves showed preferences for a specific presentation of starter concentrate during the preweaning period, offering that presentation during preweaning would help calves through the transition toward a full solid diet. The objectives of this research were to determine strategies for stimulating concentrate intake (and growth performance) early in life using preferred ingredients in the formulation of starter concentrates for young calves, and quantifying the potential changes (and their consequences) in preferences for feed presentation before and after weaning.

\section{MATERIALS AND METHODS}

\section{Experiment 1}

Sixty-three Holstein male calves $(9 \pm 0.9$ d old, $41.4 \pm 1.26 \mathrm{~kg}$ of $\mathrm{BW}$ ) were randomly distributed to 3 groups, each receiving 1 of the following solid feeds: (1) a pelleted starter feed containing wheat, a highly preferred energy source, and soybean meal, a highly preferred protein source (WS); (2) a pelleted starter feed containing wheat, a highly preferred energy source, and canola meal, a poorly preferred protein source (WC); and (3) a pelleted starter feed containing oats, a poorly preferred energy source, and soybean meal, a highly preferred protein source (OS). The ingredients and nutrient composition of these 3 starter feeds are described in Table 1.

Calves were purchased from commercial farms, raised in the facilities of Torre Marimon (Caldes de Montbui, Spain), and managed according to the recommenda- tions of the Animal Care Committee of Institut de Recerca i Tecnología Agroalimentàries (IRTA). Animals were housed in individual pens $(1.6 \times 1.0 \mathrm{~m})$ and bedded with sawdust. Three days after arrival, calves were vaccinated against respiratory syncytial virus (Rispoval RS; Pfizer Animal Health, Madrid, Spain). All calves received the same milk replacer (MR) containing $25 \%$ CP and $19.2 \%$ fat (Sprayfo Excellent 60; Sloten BV, Deventer, the Netherlands). Milk replacer was offered in 2-L bottles twice daily at 0700 and $1600 \mathrm{~h}$. During the first $7 \mathrm{~d}$ of the study, calves were offered 4 $\mathrm{L}$ of $\mathrm{MR} / \mathrm{d}$ at $12.5 \% \mathrm{DM}$ concentration. Then, calves received $6 \mathrm{~L}$ of $\mathrm{MR} / \mathrm{d}$ at $12.5 \% \mathrm{DM}$ concentration until d 35 of the study. From d 36 to 42 of the study, calves received only a morning feeding of $3 \mathrm{~L}$ at $12.5 \% \mathrm{DM}$. Calves were weaned at d 43of the study, and the study ended on d $56(65 \pm 0.9$ d old $)$.

A pelleted starter feed and barley straw $(85 \% \mathrm{NDF}$, $58 \% \mathrm{ADF}, 2.4 \% \mathrm{CP}$, on a DM basis) were fed ad libitum in 2 separate buckets $1 \mathrm{~h}$ after the morning MR. Straw was chopped using a forage chopper machine

Table 1. Ingredient and chemical composition (DM basis) of experimental concentrates fed to calves in experiment $1^{1}$

\begin{tabular}{|c|c|c|c|}
\hline Item & WS & WC & OS \\
\hline \multicolumn{4}{|l|}{ Ingredient, \% } \\
\hline Wheat meal & 22.0 & 22.0 & - \\
\hline Corn meal & 24.0 & 18.0 & 26.5 \\
\hline Barley meal & 11.7 & 9.2 & 17.2 \\
\hline Oats meal & - & - & 24.0 \\
\hline Soybean meal & 17.5 & - & 18.5 \\
\hline Wheat middlings & 12.0 & 12.0 & 12.0 \\
\hline Canola meal & - & 15.0 & - \\
\hline Peas meal & - & 12.0 & - \\
\hline Corn dried distillers grains & - & 10.0 & - \\
\hline Soybean hulls & 10.5 & - & - \\
\hline Tallow & 0.5 & - & - \\
\hline Premix $^{2}$ & 0.2 & 0.2 & 0.2 \\
\hline Calcium carbonate & 0.5 & 0.5 & 0.5 \\
\hline Dicalcium phosphate & 0.3 & 0.3 & 0.3 \\
\hline Sodium chloride & 0.8 & 0.8 & 0.8 \\
\hline \multicolumn{4}{|l|}{ Chemical composition } \\
\hline $\mathrm{CP}, \%$ & 18.4 & 18.3 & 20.1 \\
\hline NDF, $\%$ & 22.4 & 22.9 & 19.7 \\
\hline $\mathrm{ADF}, \%$ & 10.9 & 10.5 & 8.9 \\
\hline Starch, \% & 43.8 & 44.0 & 43.7 \\
\hline Ether extract, \% & 4.5 & 5.3 & 4.1 \\
\hline Ash, $\%$ & 5.4 & 5.2 & 6.3 \\
\hline $\mathrm{ME},{ }^{3} \mathrm{Mcal} / \mathrm{kg}$ & 2.92 & 3.00 & 3.05 \\
\hline
\end{tabular}

${ }^{1} \mathrm{WS}=$ concentrate based on wheat and soybean meal; $\mathrm{WC}=$ concentrate based on wheat and canola: OS = concentrate based on oat meal and soybean meal.

${ }^{2}$ Mineral and vitamin composition: vitamin A 2,500,000 IU $/ \mathrm{kg}$, vitamin $\mathrm{D}_{3} 500,000 \mathrm{IU} / \mathrm{kg}$, vitamin E 1,500 IU $/ \mathrm{kg}$, vitamin $\mathrm{B}_{1} 125 \mathrm{mg} / \mathrm{kg}$ vitamin $\mathrm{B}_{2} 125 \mathrm{mg} / \mathrm{kg}$, ferrous sulfate $5,750 \mathrm{mg} / \mathrm{kg}$, zinc oxide 8,750 $\mathrm{mg} / \mathrm{kg}$, cupric sulfate $2,500 \mathrm{mg} / \mathrm{kg}$, manganous oxide $7,500 \mathrm{mg} / \mathrm{kg}$, cobalt $100 \mathrm{mg} / \mathrm{kg}$, potassium iodide $150 \mathrm{mg} / \mathrm{kg}$, sodium selenite 25 $\mathrm{mg} / \mathrm{kg}$, magnesium oxide $12,000 \mathrm{mg} / \mathrm{kg}$.

${ }^{3}$ Calculated using NRC (2001) equations. 
(Seco, Curtalo, Italy) to reach the following particle size distribution: $47 \%>20 \mathrm{~mm}, 31 \%$ between 8 and 20 $\mathrm{mm}$, and $22 \%<8 \mathrm{~mm}$, according to Penn State Particle Separator (Nasco, Fort Atkinson, WI). Water was offered ad libitum throughout the study.

Starter feed, MR, and forage intakes were recorded daily on an individual basis. Calves were weighed weekly. Ruminal fluid was obtained via a stomach tube 2 to $3 \mathrm{~h}$ after offering the concentrate starter feed at $\mathrm{d}$ 30 and 50 of the study to measure rumen $\mathrm{pH}$ using a portable $\mathrm{pH}$ meter ( $\mathrm{pH} 25$; Crison, Barcelona, Spain).

\section{Experiment 2}

Thirty-seven Holstein $\times$ White Blue Belgian crossbreed female calves $(4 \pm 0.3 \mathrm{~d}$ old, $42.7 \pm 0.81 \mathrm{~kg}$ of BW) were raised in a commercial farm (Recria Segle XXI, Vilanant, Spain), and managed according to the recommendations of the Animal Care Committee of IRTA. After arrival, calves received $1 \mathrm{~mL}$ of tulathromycin $100 \mathrm{mg} / \mathrm{mL}$ (Draxxin; Zoetis, Girona, Spain) and were housed in individual hutches $(1.10 \times 1.40$ $\mathrm{m})$ with an open exercise area $(1 \times 1.25 \mathrm{~m})$. Hutches were bedded with sawdust every $3 \mathrm{~d}$. The MR feeding program consisted of $4 \mathrm{~L}$ of $\mathrm{MR} / \mathrm{d}$ (Sereno; Celtilait, Ploudaniel, France; $23 \%$ CP, $21 \%$ fat, on a DM basis) twice a day (0830 and $1630 \mathrm{~h}$ ) using buckets at $12.5 \%$ $\mathrm{DM}$ concentration for the first $12 \mathrm{~d}$. Then, calves were fed $6 \mathrm{~L} / \mathrm{d}$ in 2 feedings at the same concentration for the next $21 \mathrm{~d}$. At d 34 of the study, MR was reduced to $3 \mathrm{~L} / \mathrm{d}$ in 1 feeding until d 41 of the study, when animals were weaned and the study completed. Water was offered ad libitum throughout the study.

Each hutch had 4 places for concentrate feed buckets that contained starter concentrate feeds with the same composition but different physical forms (Table 2): (1) meal form (ML); (2) pellet form (PL); (3) $70 \%$ pellet form plus $20 \%$ whole corn and $10 \%$ barley (WHG); and (4) $70 \%$ pellet form plus $20 \%$ steamed-rolled corn and $10 \%$ steamed-rolled barley (SRG). All ingredients in the meal form were ground using a roller mill with a screen sieve opening of $3 \mathrm{~mm}$. The mixed mash was steam-conditioned at $80^{\circ} \mathrm{C}$ with a 0.5 min retention time, and then pelleted. The pellet mill was equipped with a die ring (3.5-mm-diameter holes and $70 \mathrm{~mm}$ thick). Oats and corn were steamed-rolled after being heated to 95 to $96^{\circ} \mathrm{C}$ for $45 \mathrm{~min}$. All starter concentrates were offered ad libitum, and the location of each concentrate form in each hutch was randomized daily to avoid confounding factors due to potential site preferences. Consumption of starter feeds and MR were recorded daily on an individual basis, and calves were weighed at the beginning and at end of the study.

\section{Experiment 3}

Sixty-three Holstein male calves $(10 \pm 1.03$ d old, and $42.9 \pm 0.95 \mathrm{~kg}$ of $\mathrm{BW}$ ) were randomly allocated to 2 treatments that consisted of feeding 2 of the concentrates used in experiment 2: the pellet concentrate mixed with whole corn and barely grains (WHG) or the pellet concentrate mixed with steamed-rolled corn and barley grains (SRG). Animals were housed in individual pens $(1.6 \times 1.0 \mathrm{~m})$ bedded with sawdust. Starter feeds (Table 2) and barley straw (89\% NDF, $55 \%$ ADF, $3.5 \% \mathrm{CP}$, on a DM basis) were offered ad libitum in 2 separate buckets $1 \mathrm{~h}$ after MR was consumed in the morning. Straw was chopped using a forage chopper machine (Seco) to obtain a final particle size distribution of $48 \%>20 \mathrm{~mm}, 32 \%$ between 8 and $20 \mathrm{~mm}$ and $20 \%<8 \mathrm{~mm}$ ). Water was offered ad libitum.

Calves were purchased from commercial farms and raised in the facilities of Torre Marimon and managed according to the recommendations of the Animal Care Committee of IRTA. Three days after arrival, calves were vaccinated against respiratory syncytial virus (Rispoval RS; Pfizer Animal Health, Madrid, Spain). All calves received the same MR (H20; Corporació Alimentària Guissona, Lleida, Spain; $23.8 \%$ CP, $20 \%$ fat on a DM basis). Milk replacer was offered in 2-L bottles twice daily at 0700 and $1600 \mathrm{~h}$. During the first $8 \mathrm{~d}$ of the study, calves were offered $4 \mathrm{~L}$ of $\mathrm{MR} / \mathrm{d}$ at $12.5 \%$ $\mathrm{DM}$ concentration. Then, calves received $6 \mathrm{~L}$ of $\mathrm{MR} / \mathrm{d}$ at $12.5 \% \mathrm{DM}$ concentration until d 28 of the study. From d 29 to 43 , calves received only the morning feeding of $3 \mathrm{~L}$ at $12.5 \%$ DM. Calves were weaned at $\mathrm{d} 43$, and the study ended at d $49(59 \pm 1.03 \mathrm{~d}$ old $)$.

Starter feed, MR, and forage intakes were recorded daily on an individual basis. Calves were weighed weekly. Ruminal fluid was obtained via a stomach tube 2 to $3 \mathrm{~h}$ after offering the concentrate starter feeds at d 35 and 50 to measure rumen $\mathrm{pH}$ using a portable $\mathrm{pH}$ meter ( $\mathrm{pH} 25$; Crison), and $4 \mathrm{~mL}$ samples of rumen liquid were immediately acidified with $1 \mathrm{~mL}$ of a solution containing $2 \mathrm{~g} / \mathrm{L}$ mercuric chloride, $20 \mathrm{~mL} / \mathrm{L}$ orthophosphoric acid, and $2 \mathrm{~g} / \mathrm{L} 4$-methylvaleric (internal standard) in distilled water, and stored at $-20^{\circ} \mathrm{C}$ until VFA analyses.

To test whether calves were sorting for or against whole or steamed-rolled grains within the mixed starter concentrate, individual samples of refusals were obtained at d 19,33, and 47 to determine its CP content, which was used as a proxy for feed sorting behavior.

\section{Chemical Analyses}

In the 3 experiments, samples of MR were analyzed for $\mathrm{DM}\left(24 \mathrm{~h}\right.$ at $\left.103^{\circ} \mathrm{C}\right)$; ash $\left(4 \mathrm{~h}\right.$ at $\left.550^{\circ} \mathrm{C}\right)$; nitrogen 
Table 2. Ingredient and chemical composition (DM basis) of experimental concentrates fed to calves in experiments 2 and 3

\begin{tabular}{|c|c|c|c|c|}
\hline \multirow[b]{2}{*}{ Item } & \multicolumn{4}{|c|}{ Experiments 2 and 3} \\
\hline & Meal & Pellet & Whole & Steamed-rolled \\
\hline \multicolumn{5}{|l|}{ Ingredient, \% } \\
\hline Corn meal & 35.1 & 35.1 & 15.1 & 15.1 \\
\hline Whole corn & - & - & 20 & - \\
\hline Steamed-rolled corn & - & - & - & 20 \\
\hline Barley meal & 14.6 & 14.6 & 4.6 & 4.6 \\
\hline Whole barley & - & - & 10 & - \\
\hline Steamed-rolled barley & - & - & - & 10 \\
\hline Soybean meal & 13.3 & 13.3 & 13.3 & 13.3 \\
\hline Wheat middlings & 12.01 & 12.01 & 12.01 & 12.01 \\
\hline Sunflower meal & 3.0 & 3.0 & 3.0 & 3.0 \\
\hline Corn gluten meal & 12.0 & 12.0 & 12.0 & 12.0 \\
\hline Carob meal & 4.6 & 4.6 & 4.6 & 4.6 \\
\hline Palm oil & 2.8 & 2.8 & 2.8 & 2.8 \\
\hline Premix ${ }^{1}$ & 0.56 & 0.56 & 0.56 & 0.56 \\
\hline Calcium carbonate & 1.6 & 1.6 & 1.6 & 1.6 \\
\hline Sodium chloride & 0.35 & 0.35 & 0.35 & 0.35 \\
\hline Biosprint $^{2}$ & 0.08 & 0.08 & 0.08 & 0.08 \\
\hline \multicolumn{5}{|l|}{ Chemical composition } \\
\hline $\mathrm{CP}, \%$ & 18.3 & 17.9 & 18.0 & 17.2 \\
\hline NDF, $\%$ & 20.5 & 21.8 & 20.6 & 18.5 \\
\hline $\mathrm{ADF}, \%$ & 8.3 & 8.7 & 8.9 & 8.4 \\
\hline Starch, $\%$ & 39.2 & 40.6 & 41.8 & 45.6 \\
\hline Ether extract, \% & 4.6 & 5.9 & 6.7 & 6.3 \\
\hline Ash, $\%$ & 7.1 & 6.9 & 6.0 & 5.6 \\
\hline $\mathrm{ME},{ }^{3} \mathrm{Mcal} / \mathrm{kg}$ & 3.13 & 3.13 & 3.13 & 3.13 \\
\hline \multicolumn{5}{|c|}{$\begin{array}{l}{ }_{\mathrm{l}} \text { Mineral and vitamin composition: vitamin } \mathrm{A} 2,500,000 \mathrm{IU} / \mathrm{kg} \text {, vitamin } \mathrm{D}_{3} 500,000 \mathrm{IU} / \mathrm{kg} \text {, vitamin E } 1,500 \mathrm{IU} / \\
\mathrm{kg} \text {, vitamin } \mathrm{B}_{1} 125 \mathrm{mg} / \mathrm{kg} \text {, vitamin } \mathrm{B}_{2} 125 \mathrm{mg} / \mathrm{kg} \text {, ferrous sulfate } 5,750 \mathrm{mg} / \mathrm{kg} \text {, zinc oxide } 8,750 \mathrm{mg} / \mathrm{kg} \text {, cupric } \\
\text { sulfate } 2,500 \mathrm{mg} / \mathrm{kg} \text {, manganous oxide } 7,500 \mathrm{mg} / \mathrm{kg} \text {, cobalt } 100 \mathrm{mg} / \mathrm{kg} \text {, potassium iodide } 150 \mathrm{mg} / \mathrm{kg} \text {, sodium } \\
\text { selenite } 25 \mathrm{mg} / \mathrm{kg} \text {, magnesium oxide } 12,000 \mathrm{mg} / \mathrm{kg} \text {. }\end{array}$} \\
\hline
\end{tabular}

content using AOAC (1990) method 988.05 adapted for an automatic distiller Kjeldahl (Kjeltec Auto 1030 Analyzer, Tecator, Höganäs, Sweden) with copper sulfate/selenium as a catalyst instead of copper sulfate/ titanium dioxide; and ether extract using the method 920.39 using petroleum ether for distillation instead of diethyl ether (AOAC, 1990). Samples of starter feed and forage were analyzed for DM, ash, and CP following the methods described above; for NDF with sodium sulfite and heat-stable $\alpha$-amylase (Van Soest et al., 1991); and for ADF following the AOAC (1990) method 973.18.

The VFA content of the ruminal fluid from calves in experiment 3 was analyzed using gas chromatography (HP-6890 Series II; Agilent, Palo Alto, CA) using a capillary column $(10 \mathrm{~m} \times 0.10 \mathrm{~mm} \times 100 \mu \mathrm{m}$; DB5; Agilent).

\section{Calculations and Statistical Analyses}

In experiments 1 and 3, performance and individual intake data were analyzed separately for the preweaning (wk 1 to 6) and postweaning (wk 7) periods, using in both cases a mixed-effects model for repeated mea- sures. The statistical model included the concentrate type, the week of study, and their 2-way interaction as fixed effects. Initial BW and age were used as covariates, and animal entered the models as a random effect.

In experiment 2, we assessed preferences among the 4 different starter concentrate forms by calculating a preference ratio as follows: $\left\{\left[\mathrm{x}_{\mathrm{i}}\right] /\left[\left(\sum \mathrm{x}_{1,2,3,4} / n\right)\right]\right\}$, where $\mathrm{x}_{\mathrm{i}}$ represents concentrate DMI for each of the concentrate presentation; $\mathrm{x}_{1,2,3,4}$ represents total DMI of the 4 concentrates; and $n$ was set to the value of 4 (because 4 different concentrates were contrasted). This preference ratio was adapted from Larrinaga (2010), and assumed that if concentrates had been the same in all 4 buckets, calves would have eaten one-fourth from each bucket. Thus, values $<1$ indicate a poor preference for that concentrate form, and values $>1$ indicate a positive preference for that concentrate form. Data were analyzed using a mixed-effects model for repeated measures, considering concentrate type, week of study, and their 2-way interaction as fixed effects, and animal as a random effect.

In experiment 3, to assess whether calves were sorting for or against grains or pellets in the solid feed 
mixture offered, we calculated a preferences ratio as follows: [(mixture CP \% in the refusal)/(mixture CP \% in the offer)]. Values equal to 1 indicated no selection for or against whole or steamed-rolled grains; values $<1$ indicated less CP content in the refusal than in the initial mixture (meaning that more cereal grains were present in the refusal), indicating a selection for pellet in the mixture; and values $>1$ indicated preferences for whole or steamed-rolled grains (more CP in the refusal because it contained more pellet than cereal grains). Data were subjected to the one-sample comparison $t$ test using 1 as the reference value.

\section{RESULTS}

\section{Experiment 1}

We found no differences in DMI or growth among treatments during the pre- or postweaning periods (Table 3). However, during the preweaning period, WS calves tended $(P=0.08)$ to have gain-to-feed ratio better than that of WC calves and similar to that of OS calves. Rumen $\mathrm{pH}$ was similar for all 3 treatments, and did not change from d 30 to $50(5.6 \pm 0.07$; mean \pm SEM).

\section{Experiment 2}

The preference ratio for the 4 starter concentrate forms differed $(P<0.01)$ by day of study (Figure 1$)$. During wk 1, calves showed a lower preference for SRG than for WHG, but during wk 2, SRG was more preferred than ML and WHG. At wk 3, we found no differences in preference ratios among the 4 concentrate forms. At wk 4 and 5, SRG was most preferred, followed by WHG; ML and PL were the least preferred. In the week before weaning, SRG and ML were the most preferred, followed by WHG; PL was the least preferred.

\section{Experiment 3}

We observed no differences in performance between calves fed WHG and SRG (Table 4), but starter concentrate and total DMI were greater in WHG than SRG calves during wk 5 to 6 (Figure 2). However, these differences disappeared after weaning. Calves fed SRG sorted $(P<0.05)$ in favor of steamed-rolled grains and against pelleted concentrate throughout the study (Figure 3$)$. In contrast, WHG calves sorted $(P<0.05)$ in favor of pelleted concentrate at d 47 of the study, but showed no sorting preference at d 19 and 33 (Figure 3).

Calves offered SRG had lower $(P<0.01)$ rumen $\mathrm{pH}$ than calves fed WHG, and total rumen VFA concentrations were numerically greater in SRG than in WHG calves (Table 5). The rumen VFA profile was also altered by the physical form of the grain (Table 5). In general, the molar proportion of butyrate increased $(P<0.01)$ with time; those of isovalerate and isopropionate decreased $(P<0.01)$; and those of propionate tended to decrease $(P=0.10)$ over time. The molar proportions of isobutyrate and isovalerate were greater $(P<0.01)$ in the rumens of calves receiving WHG concentrates than in those receiving SRG concentrates (Table 5). In

Table 3. Performance and intake of calves fed different starter concentrates formulated based on sensory preferences (experiment 1)

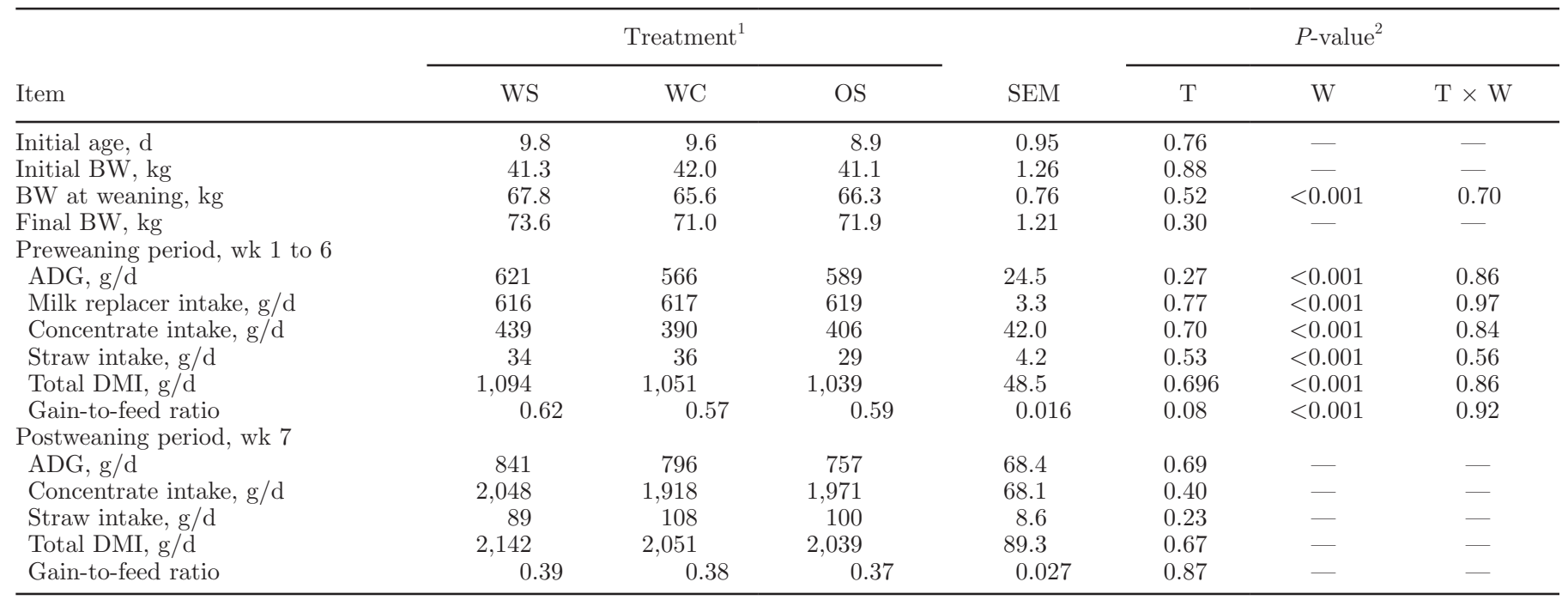

${ }^{1} \mathrm{WS}=$ concentrate based on wheat and soybean meal; $\mathrm{WC}=$ concentrate based on wheat and canola meal; OS = concentrate based on oats and soybean meal.

${ }^{2} \mathrm{~T}=$ effect of type of starter concentrate; $\mathrm{W}=$ effect of week; $\mathrm{T} \times \mathrm{W}=$ interaction between type of starter concentrate and week. 


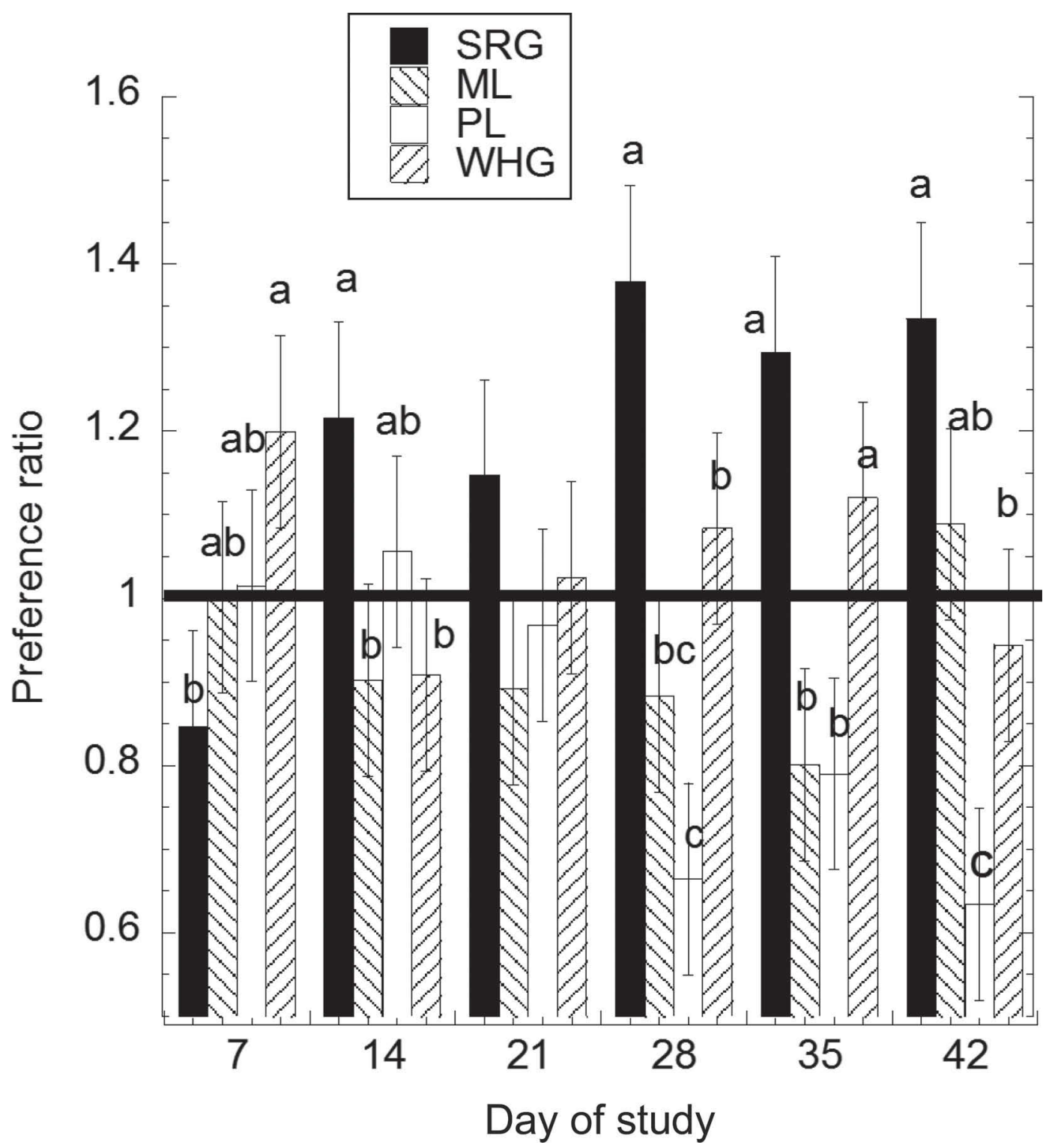

Figure 1. Preference ratios of preweaned calves for a mixture of pellets and steamed-rolled corn and barley grains (SRG), a meal form concentrate (ML), a pelleted concentrate (PL), or a mixture of pellets and whole corn and barley grains (WHG). Values with different letters (a-c) among concentrate types within day of study differ at $P<0.05$ (experiment 2). Error bars are the SEM.

contrast, acetate rumen molar proportions were greater $(P<0.01)$ and butyrate molar proportions tended $(P$ $=0.10)$ to be lower in SRG than WHG calves after weaning (at $50 \mathrm{~d}$ ). Consequently, the ratio of acetate to propionate was greater $(P<0.05)$ in SRG than in WHG calves at $50 \mathrm{~d}$.

\section{DISCUSSION}

Several studies (Miller-Cushon et al., 2014a,b; Webb et al., 2014) have demonstrated that calves have preferences for different sensory and physical characteristics of feeds, and that they have the capacity to select for determined types of feeds and forms. However, the present study showed that using preferred ingredients when formulating starter concentrate for calves did not lead to better performance by promoting concentrate intake. Montoro and Bach (2012) offered to 2 groups of young calves either a pelleted concentrate or the same ingredients but in separate buckets. Although calves that were fed the ingredients separately had a clear preference for soybean meal (a higher relative consumption of this ingredient compared with the pelleted concentrate formula), the total DMI of calves was similar in both groups, suggesting that allowing calves to select preferred ingredients (based on sensory 
Table 4. Performance and intake of calves fed a starter concentrate containing a mixture of pellets and whole or steamed-rolled cereal grains (experiment 3)

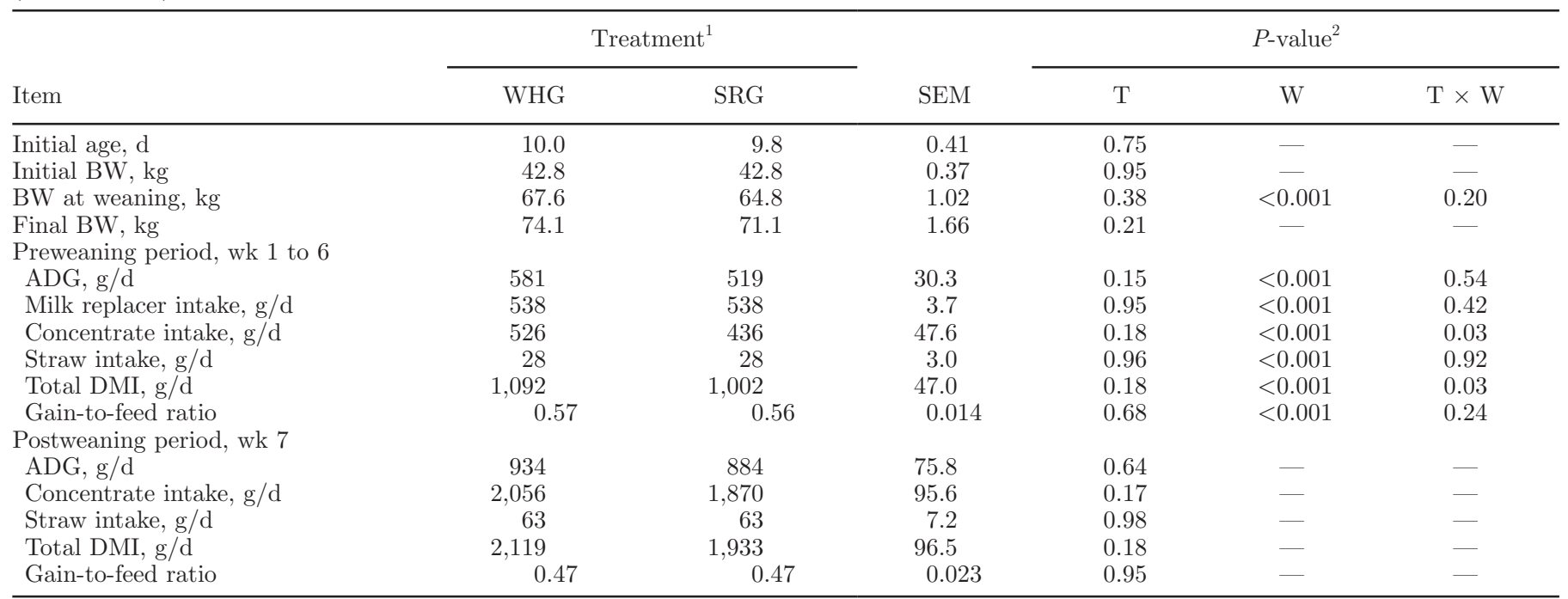

${ }^{1} \mathrm{WHG}=$ concentrate containing a mixture of pellets and whole grains; SRG = concentrate containing a mixture of pellets and steamed-rolled grains.

${ }^{2} \mathrm{~T}=$ effect of the type of concentrate; $\mathrm{W}=$ effect of week of study; $\mathrm{T} \times \mathrm{W}=$ interaction between type of concentrate and week.

perception) was not a good strategy for fostering DMI during the preweaning period. In contrast to the present study, Khan et al. (2007, 2008) compared 4 different concentrates differing in starch source (barley, corn,

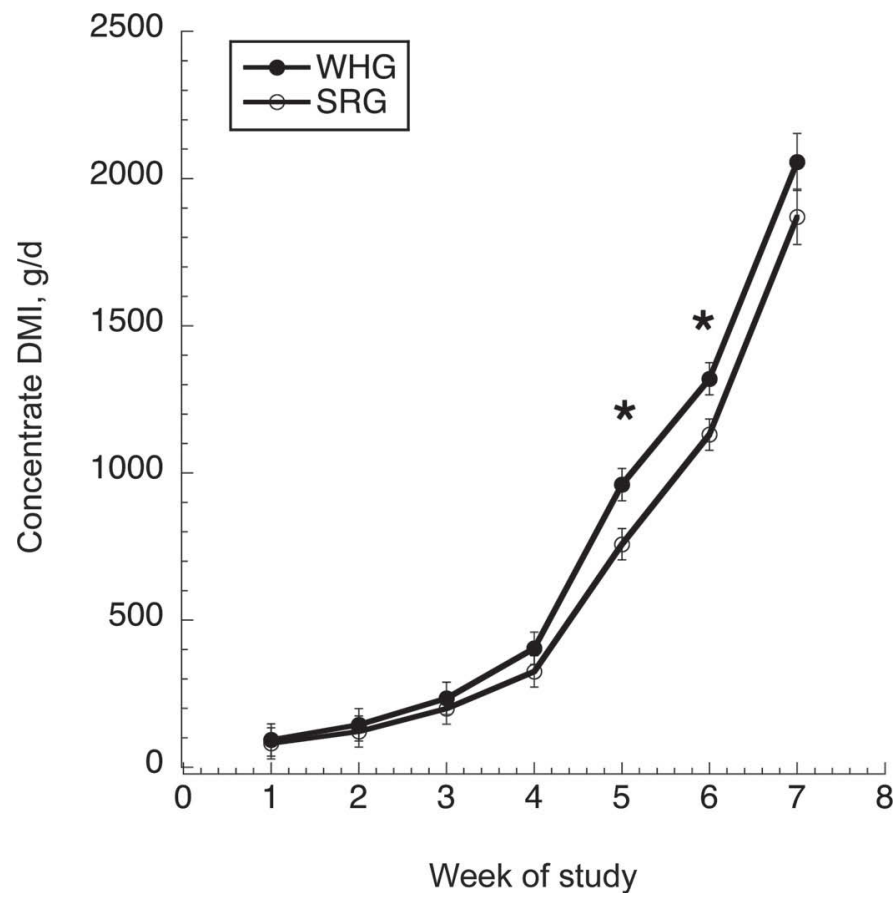

Figure 2. Evolution of concentrate DMI of calves fed a starter concentrate containing a mixture of pellets and whole (WHG; $\bullet$ ) or steamed-rolled (SRG; O) cereal grains (experiment 3 ). ${ }^{*}$ Intake differs at $P<0.05$ between concentrate type and time. Error bars are the SEM.

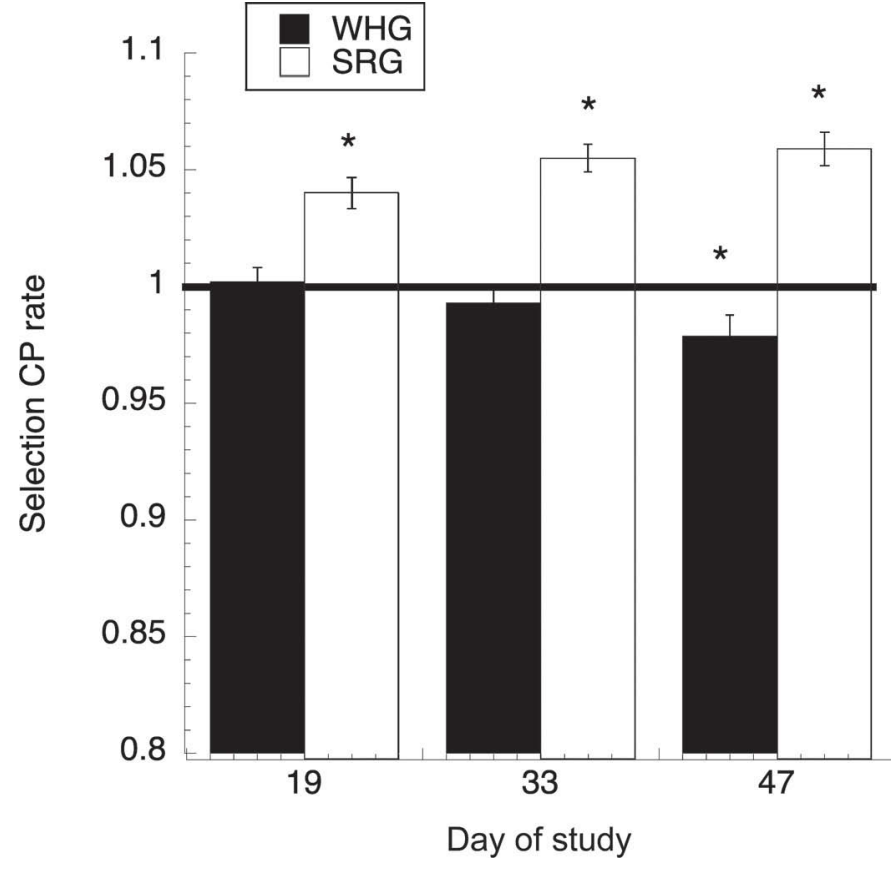

Figure 3. Sorting activity measured as CP change throughout the study in calves fed a starter concentrate containing a mixture of pellets and whole (WHG) or steamed-rolled (SRG) cereal grains (experiment 3 ). ${ }^{*}$ Selection rates differ from 1 at $P<0.05$. Values equal to 1 indicate no selection for or against whole or steamed-rolled grains, values $<1$ indicate a selection for pellet in the mixture, and values $>1$ indicate preferences to consume whole or steamed-rolled grains. Error bars are the SEM. 
Table 5. Rumen $\mathrm{pH}$ and volatile fatty acid concentration of calves fed a starter concentrate containing a mixture of pellets and whole or steamed-rolled cereal grains (experiment 3)

\begin{tabular}{|c|c|c|c|c|c|c|}
\hline \multirow[b]{2}{*}{ Item } & \multicolumn{2}{|c|}{ Treatment $^{1}$} & \multirow[b]{2}{*}{ SEM } & \multicolumn{3}{|c|}{$P$-value ${ }^{2}$} \\
\hline & WHG & SRG & & $\mathrm{T}$ & $\mathrm{W}$ & $\mathrm{T} \times \mathrm{W}$ \\
\hline Rumen pH & 6.5 & 6.1 & 0.12 & 0.004 & 0.848 & 0.619 \\
\hline Total VFA, mM & 78.7 & 89.5 & 6.63 & 0.113 & 0.960 & 0.700 \\
\hline \multicolumn{7}{|l|}{ VFA, mol/100 mol } \\
\hline Acetate & 48.1 & 49.4 & 1.05 & 0.214 & 0.640 & 0.006 \\
\hline Propionate & 37.7 & 37.4 & 1.03 & 0.856 & 0.106 & 0.352 \\
\hline Isobutyrate & 0.63 & 0.44 & 0.042 & $<0.001$ & $<0.001$ & 0.386 \\
\hline Butyrate & 9.7 & 8.7 & 0.87 & 0.267 & 0.010 & 0.100 \\
\hline Isovalerate & 0.56 & 0.38 & 0.043 & $<0.001$ & $<0.001$ & 0.259 \\
\hline Valerate & 3.7 & 4.1 & 0.38 & 0.383 & 0.122 & 0.178 \\
\hline Acetate:propionate & 1.37 & 1.50 & 0.094 & 0.211 & 0.088 & 0.049 \\
\hline
\end{tabular}

${ }^{1} \mathrm{WHG}=$ concentrate containing a mixture of pellets and whole grains; SRG = concentrate containing a mixture of pellets and steamed-rolled grains.

${ }^{2} \mathrm{~T}=$ effect of the type of concentrate; $\mathrm{W}=$ effect of week of study; $\mathrm{T} \times \mathrm{W}=$ interaction between type of concentrate and week.

oats, or wheat) and reported differences in concentrate and mixed dry hay DMI, as well as differences in rumen $\mathrm{pH}$. In that study, corn-based concentrates (followed by wheat-based concentrates) elicited the greatest starter concentrate and mixed dry hay DMI by calves. Authors attributed these differences to the greatest rumen $\mathrm{pH}$ determined in calves receiving the corn-based concentrate. It is likely that the differences in rumen $\mathrm{pH}$ in Khan et al. (2008) were partly due to differences in the intake of mixed dry hay among treatments. In the present study, no difference in straw intake was observed among treatments, and the ingredient composition of the starter concentrate per se did not provoke changes in rumen $\mathrm{pH}$ (at 30 and $50 \mathrm{~d}$ ).

Although experiment 1 was designed to evaluate the potential effects of using preferred ingredients by stimulating solid DMI in young calves, some differences were observed in the gain-to-feed ratio, which was greater in calves receiving WS diets than calves consuming WC diets during the preweaning period. The main difference between these 2 concentrates was the $\mathrm{CP}$ source: either soybean in WS or canola, peas, and corn distillers grains in WC. The differences in gain-to-feed ratio may be attributed to differences in concentrate digestibility and amino acid supply. Khorasani et al. (1990) fed a diet based on corn and either soybean meal or canola meal to 75-d-old calves, and they observed greater DM and CP digestibility with diets based on soybean than in diets based on canola. Similarly, when Hadam et al. (2016) replaced all the soybean meal with canola meal in a starter concentrate, calves fed canola meal had similar concentrate intake to those fed soybean meal, but ADG and feed efficiency decreased, as observed in the present study.

Calves showed a clear preference for SRG concentrates starting at d 14 of the study (18 d of age), with little preference change throughout the preweaning period. Palatability, which is influenced by taste, smell, texture, nutrients, or toxins (Quaranta et al., 2006), can initially determine preference for an ingredient. However, the postingestive effects of a palatable feed could lead to changes in degree of preference (Provenza, 1995). In most studies (Beharka et al., 1998; Gimeno et al., 2015; Terré et al., 2015), unground grain diets showed greater rumen $\mathrm{pH}$ and a positive effect in stimulating concentrate DMI when compared with a ground diet. Therefore, a preference for a concentrate containing whole or steamed-rolled grains over one containing ground grains in a pelleted or meal form could be expected. In fact, Bateman et al. (2009) concluded that calves had low acceptability for starter concentrates containing fines, resulting in reduced starter intake and ADG.

Grains in starter concentrate were well accepted by calves in experiment 2 , and we found no marked changes in preferences throughout the preweaning period. Several authors have highlighted the importance of feeding grains in the starter concentrate of calves (Porter et al., 2007; Hill et al., 2012). Experiment 3 was performed to assess the degree of feed selection in mixed pelleted and grain concentrates and its potential consequences for performance and rumen fermentation. Offering calves whole grains stimulated starter concentrate intake when the DMI of calves was $\geq 800 \mathrm{~g} / \mathrm{d}$. However, the increase in DMI was not sufficiently high to elicit changes in performance (ADG and gain-to-feed ratio). Steamed-rolled processing may have improved concentrate digestibility (Mathison, 1996; Ferraretto et al., 2013) compared with whole grains, and the lower intake by calves that were offered steamed-rolled grain concentrates may have been compensated for by an improvement in feed digestibility. Such differences in 
intake have been previously reported in the literature when comparing whole with ground grains (Pezhveh et al., 2014) or whole with steam-flaked corn (Lesmeister and Heinrichs, 2004).

Similarly, changes in rumen $\mathrm{pH}$ and total VFA concentration have been reported in the literature (Beharka et al., 1998; Lesmeister and Heinrichs, 2004). The increase in rumen VFA concentration and the decrease in rumen $\mathrm{pH}$ observed with steamed-rolled grains may be attributable to a greater availability of starch from processed grains (Björck et al., 1984). In contrast to Lesmeister and Heinrichs (2004), in the present study calves had access to straw and were able to compensate, if needed, for low rumen $\mathrm{pH}$ because of processed grains. However, differences in rumen $\mathrm{pH}$ between calves consuming whole or steamed-rolled concentrates may not have been sufficient to provoke changes in straw intake, in part because rumen $\mathrm{pH}$ values were $>6.0$ in both treatments in the present study, in contrast to Lesmeister and Heinrichs (2004), who reported values between 5.4 and 5.8. Suarez-Mena et al. (2015) observed only minimal changes in the rumen fermentation profile when offering whole or ground oats from wk 1 to 4 of age, and attributed the lack of difference to the young age of calves. Similarly, in the present study the major changes in rumen fermentation profile were observed at $50 \mathrm{~d}$ but not at $35 \mathrm{~d}$. Similar to Beharka et al. (1998), in the present study, the butyrate molar proportion increased and branched-chain VFA decreased with time. The decrease in rumen molar proportion of branched-chain VFA observed in calves receiving the SRG concentrates suggested a decrease of protein degradation, because these VFA are derived mainly from the fermentation of leucine and valine. The selection for cereal grains (with lower CP content than pelleted concentrate) in SRG calves might partially explain the lower proportion of branched-chain VFA in SRG calves than in WHG calves. Increases in the proportion of propionate may be expected as the processing of grains increased, but we observed no difference in rumen molar proportions of propionate between treatments. The greatest starch availability in SRG diets might be compensated for by the increase of concentrate intake in WHG calves. Several hypotheses can be formulated to explain the lower rumen molar proportion of acetate and the greater rumen molar proportion of butyrate in WHG calves compared with SRG calves at 50 d. In the present study, during the week after weaning, SRG calves consumed $3.3 \%$ of the total solid intake as straw, and WHG calves 3\%. Generally, fiber intake is associated with an increase in acetate production in the rumen. Therefore, differences in the percentage of straw intake might have influenced the rumen acetate profile. The absorption rate of VFA might also be influenced by rumen $\mathrm{pH}$. At low $\mathrm{pH}$, the absorption rate is greater for butyric acid, followed by propionic and acetic acids (Dijkstra et al., 1993). Then, the lower rumen $\mathrm{pH}$ observed in the rumen of SRG compared with WHG calves may have led to an accumulation of acetate in the rumen of SRG calves. Last, differences in rumen microbiota, such as an increase in butyrate-producing bacteria in WHG calves, or the metabolism of rumen epithelia (ergo an increase of butyrate metabolized by epithelial cells) in SRG calves, might also have induced changes in the rumen VFA profile.

The ability of calves to sort for different feeds in the same bucket has been previously demonstrated (MillerCushon et al., 2014b). Sorting may have negative consequences because it may cause dietary imbalances, and it can cause environmental problems by increasing nitrogen excretion to the environment if animals sort for feeds rich in CP. Although SRG calves sorted against the pelleted concentrate throughout the study, this sorting behavior, again, was not sufficiently large to affect performance.

\section{CONCLUSIONS}

When preweaned calves were given the opportunity to choose different concentrate forms, they showed a preference for a concentrate that contained a mix of pellets and corn or barley steamed-rolled grains over concentrates presented as meal, as pellets, or as a mix of pellets and whole grains of corn and barley. However, when they could not choose among different feeds, offering calves preferred ingredients, such as wheat and soybean meal, in a pelleted concentrate or presenting them in a preferred form (pelleted with steamed-rolled cereal grains) did not promote an increase in starter concentrate intake or improve performance. Feeding pelleted starter concentrates containing ingredients preferred by calves did not stimulate concentrate intake, and starter concentrates containing steamedrolled grains resulted in lower concentrate intake and rumen $\mathrm{pH}$, greater sorting behavior, and similar growth performance compared with starter concentrates containing whole grains.

\section{ACKNOWLEDGMENTS}

We thank Ministerio de Agricultura, Alimentación y Medio Ambiente (Madrid, Spain) and the Instituto Nacional de Investigación y Tecnología Agraria y Alimentària (Madrid, Spain) for partial financial support through the grant MAGRAMA 20130020000779. We also thank Laia Gifré, Maria Vidal, Gemma Araujo, Daniel Sabrià, Lidia Hospital, Georgina Maynou, Jordi Casino, and Joan Suriñach from IRTA (Caldes de 
Montbui, Spain); Dídac Vieites from Recria Segle XXI (Vilanant, Spain); Javier Heras from Vether Girona SL (Vilademuls, Spain); and Armando Pérez from Grupo Alimentario Guissona (Guissona, Spain) for their help with calf management and care.

\section{REFERENCES}

AOAC. 1990. Official Methods of Analysis. Association of Official Analytical Chemists, Arlington, VA.

Bach, A., J. Ahedo, and A. Ferrer. 2010. Optimizing weaning strategies of dairy replacement calves. J. Dairy Sci. 93:413-419.

Bach, A., A. Giménez, J. L. Juaristi, and J. Ahedo. 2007. Effects of physical form of a starter for dairy replacement calves on feed intake and performance. J. Dairy Sci. 90:3028-3033.

Bateman, H. G., II, T. M. Hill, J. M. Aldrich, and R. L. Schlotterbeck. 2009. Effects of corn processing, particle size, and diet form on performance of calves in bedded pens. J. Dairy Sci. 92:782-789.

Beharka, A. A., T. G. Nagaraja, J. L. Morrill, G. A. Kennedy, and R. D. Klemm. 1998. Effects of form of the diet on anatomical, microbial, and fermentative development of the rumen of neonatal calves. J. Dairy Sci. 81:1946-1955.

Beiranvand, H., M. Khorvash, G. R. Ghorbani, A. Homayouni, L. Bachmann, and S. Kargar. 2014. Evaluation of ketogenic vs glucogenic substrates as energy sources in starter diets for Holstein dairy calves. Can. J. Anim. Sci. 94:717-723.

Björck, I., N.-G. Asp, D. Birkhed, and I. Lunquist. 1984. Effects of processing on availability of starch for digestion in vitro and in vivo; I Extrusion cooking of wheat flours and starch. J. Cereal Sci. 2:91-103.

Castells, L., A. Bach, G. Araujo, C. Montoro, and M. Terré. 2012. Effect of different forage sources on performance and feeding behavior of Holstein calves. J. Dairy Sci. 95:286-293.

Dijkstra, J., H. Boer, J. Van Bruchem, M. Bruining, and S. Tamminga 1993. Absorption of volatile fatty acids from the rumen of lactating dairy cows as influenced by volatile fatty acid concentration, $\mathrm{pH}$ and rumen liquid volume. Br. J. Nutr. 69:385-396.

Ferraretto, L. F., P. M. Crump, and R. D. Shaver. 2013. Effect of cereal grain type and corn grain harvesting and processing methods on intake, digestion, and milk production by dairy cows through a meta-analysis. J. Dairy Sci. 96:533-550.

Franklin, S. T., D. M. Amaral-Philips, J. A. Jackson, and A. A. Campbell. 2003. Health and performance of Holstein calves that suckled or were hand-fed colostrum and were fed one of three physical forms of starter. J. Dairy Sci. 86:2145-2153.

Gimeno, A., A. Al Alami, L. Abecia, A. de Vega, M. Fondevila, and C. Castrillo. 2015. Effect of type (barley vs maize) and processing (grinding vs dry rolling) of cereal on ruminal fermentation and microbiota of beef calves during the early fattening period. Anim. Feed Sci. Technol. 199:113-126.

Hadam, D., J. Kanski, K. Burakowska, G. B. Penner, Z. M. Kowalski, and P. Górka. 2016. Short communication: Effect of canola meal use as a protein source in a starter mixture on feeding behavior and performance of calves during the weaning transition. J. Dairy Sci. 99:1247-1252.

Hill, S. R., B. A. Hopkins, S. Davidson, S. M. Bolt, D. E. Díaz, C. Brownie, T. Brown, G. B. Huntington, and L. W. Whitlow. 2009. The addition of cottonseed hulls to the starter and supplementation of live yeast or mannanoligosaccharide in the milk for young calves. J. Dairy Sci. 92:790-798.

Hill, T. M., H. G. Bateman II, J. M. Aldrich, and R. L. Schlotterbeck. 2012. High-starch, coarse-grain, low-fiber diets maximize growth of weaned dairy calves less than 4 months of age. Prof. Anim. Sci. $28: 325-331$.
Khan, M. A., H. J. Lee, W. S. Lee, H. S. Kim, S. B. Kim, K. S. Ki, S. J. Park, J. K. Ha, and Y. J. Choi. 2007. Starch source evaluation in calf starter: I. Feed consumption, body weight gain, structural growth, and blood metabolites in Holstein calves. J. Dairy Sci. 90:5259-5268

Khan, M. A., H. J. Lee, W. S. Lee, H. S. Kim, S. B. Kim, S. J. Park, K. S. Baek, J. K. Ha, and Y. J. Choi. 2008. Starch source evaluation in calf starter: II. Ruminal parameters, rumen development, nutrient digestibilities, and nitrogen utilization in Holstein calves. J. Dairy Sci. 91:1140-1149.

Khan, M. A., D. M. Weary, and M. A. G. von Keyserlingk. 2011. Hay intake improves performance and rumen development of calves fed higher quantities of milk. J. Dairy Sci. 94:3547-3553.

Khorasani, G. R., W. C. Sauer, L. Ozimek, and J. J. Kennelly. 1990. Protein and amino acids in the digestive tract of young ruminants. J. Anim. Sci. 68:3421-3428.

Larrinaga, A. 2010. A univariate analysis of variance design for multiple-choice feeding-preference experiments: A hypothetical example with fruit-eating birds. Acta Oecol. 36:141-148.

Lesmeister, K. E., and A. J. Heinrichs. 2004. Effects of corn processing on growth characteristics, rumen development, and rumen parameters in neonatal dairy calves. J. Dairy Sci. 87:3439-3450.

Lesmeister, K. E., and A. J. Heinrichs. 2005. Effects of adding extra molasses to a texturized calf starter on rumen development, growth characteristics, and blood parameters in neonatal dairy calves. J. Dairy Sci. 88:411-418.

Mathison, G. W. 1996. Effects of processing on the utilization of grain by cattle. Anim. Feed Sci. Technol. 58:113-125.

Miller-Cushon, E. K., C. Montoro, I. R. Ipharraguerre, and A. Bach 2014a. Dietary preferences in dairy calves for feed ingredients high in energy and protein. J. Dairy Sci. 97:1634-1644.

Miller-Cushon, E. K., M. Terré, T. J. De Vries, and A. Bach. 2014b. The effect of palatability of protein source on dietary selection in dairy calves. J. Dairy Sci. 97:4444-4454.

Montoro, C., and A. Bach. 2012. Voluntary selection of starter feed ingredients offered separately to nursing calves. Livest. Sci. 149:6269 .

NRC. 2001. Nutrient Requirements of Dairy Cattle. 7th rev. ed. Natl. Acad. Press, Washington, DC.

Pezhveh, N., G. R. Ghorbani, P. Rezamand, and M. Khorvash. 2014 Effects of different physical forms of wheat grain in corn-based starter on performance of young Holstein dairy calves. J. Dairy Sci. 97:6382-6390.

Porter, J. C., R. G. Warner, and A. F. Kertz. 2007. Effect of fiber level and physical form of starter on growth and development of dairy calves fed no forage. Prof. Anim. Sci. 23:395-400.

Provenza, F. D. 1995. Postingestive feedback as an elementary determinant of food preference and intake in ruminants. J. Range Manage. 48:2-17.

Quaranta, A., A. G. D'Alessandro, A. Frate, G. E. Coltella, G. Martemucci, and G. Casamassima. 2006. Behavioural response towards twelve feedstuffs in lambs. Small Rumin. Res. 64:60-66.

Suarez-Mena, F. X., A. J. Heinrichs, C. M. Jones, T. M. Hill, and J. D. Quigley. 2015. Digestive development in neonatal dairy calves with either whole or ground oats in the calf starter. J. Dairy Sci. 98:3417-3431

Terré, M., Ll. Castells, M. A. Khan, and A. Bach. 2015. Interaction between the physical form of the starter feed provision on growth performance of Holstein calves. J. Dairy Sci. 98:1101-1109.

Van Soest, P. J., J. B. Robertson, and B. A. Lewis. 1991. Methods for dietary fiber, neutral detergent fiber, and nonstarch polysaccharides in relation to animal nutrition. J. Dairy Sci. 74:3583-3597.

Webb, L. E., M. B. Jensen, B. Engel, C. G. van Reenen, W. J. J. Gerrits, I. J. M. de Boer, and E. A. M. Bokkers. 2014. Chopped or long roughage: What do calves prefer? Using cross point analysis of double demand function. PLoS ONE 9:e88778. 